\title{
Effect of Geometrical Parameters on the Coefficient of Performance of the Ranque-Hilsch Vortex Tube
}

\author{
Seif T. Abdelghany ${ }^{1}$, Hamdy A. Kandil ${ }^{2}$ \\ ${ }^{1}$ Mechatronics Engineering Department, German University in Cairo, Cairo, Egypt \\ ${ }^{2}$ Mechanical Engineering Department, Faculty of Engineering, Alexandria University, Alexandria, Egypt \\ Email: seif.abdelghany@gmail.com, hamdykandil@gmail.com
}

How to cite this paper: Abdelghany, S.T. and Kandil, H.A. (2018) Effect of Geometrical Parameters on the Coefficient of Performance of the Ranque-Hilsch Vortex Tube. Open Access Library Journal, 5: e4347. https://doi.org/10.4236/oalib.1104347

Received: January 17, 2018

Accepted: February 20, 2018

Published: February 23, 2018

Copyright ( $\odot 2018$ by authors and Open Access Library Inc.

This work is licensed under the Creative Commons Attribution International License (CC BY 4.0).

http://creativecommons.org/licenses/by/4.0/

\section{(c) (i) Open Access}

\begin{abstract}
The Ranque-Hilsch vortex tube is a simple device with no moving parts and no mechanical operations. This tube separates the inlet air into two distinctive regions; an outward high temperature region and an inner low-temperature one. A computational study of the vortex tube is presented in this article using the ANSYS Fluent ${ }^{\circledR}$ software whose results showed good agreement with the experimental measurements. The effects of different geometrical parameters such as the tube length to diameter ratio and the cold orifice size on the coefficient of performance of the tube were investigated. The results showed that the coefficient of performance (COP) of the tube is highly affected by the tube length to diameter ratio $(L / D)$, and this effect varies when operating at different cold mass fractions where the maximum coefficient of performance occur at cold mass fraction of 0.64 . The results also showed that the coefficient of performance of the tube is also affected by the cold orifice to tube diameter ratio $\left(d_{c} / D\right)$ and that the maximum $(\mathrm{COP})$ at any $\left(d_{c} / D\right)$ ratio occurs also at a cold mass fraction of 0.64 .
\end{abstract}

\section{Subject Areas}

Mechanical Engineering

\section{Keywords}

Ranque-Hilsch Vortex Tube (RHVT), Cold Orifice, Maxwell's Demon, Refrigeration, Computational Fluid Dynamics (CFD), ANSYS Fluent

\section{Introduction}

The vortex tube (VT) is a device with a simple geometry without moving me- 
chanical parts [1] [2] [3] [4]. It enables the separation of hot and cold air vortices from the inlet air, as it is supplied with compressed air that flows tangentially through the inlet nozzles [5] [6] [7]. The Vortex tube was first discovered in 1933 by Georges J. Ranque [8], and in 1947 Rudolf Hilsch improved and modified the design of Ranque [9]. The vortex tube consists of many parts [10] [11] including one or more inlet nozzles, a vortex chamber, a control valve that is located at the hot outlet, a cold orifice and a working tube [12]. When compressed air is injected tangentially through the inlet nozzles into the vortex chamber a strong rotational flow (vortex) is formed at the periphery of the tube wall [13]. The vortex propagates till the end of the tube where some air leaves the tube via the hot outlet. However, adjusting the control valve at the hot outlet forces the rest of the air to reverse its direction and exit from the cold outlet along the centerline of the tube. It is noted that two vortices occur inside the tube, one at the periphery of the tube which exits at the hot outlet at a temperature much higher than the inlet temperature and the other one at the core of the tube with opposite flow direction which exits at the cold orifice with a temperature much lower than the inlet temperature.

The VT is used in many applications such as cooling of airborne electronic components, cooling of gas samples, and cooling of soldered parts including spot welding and ultrasonic welding. It is also used in the separation of air into nitrogen and oxygen rich fluid stream [14] [15]. The VT has many advantages [16] [17] [18] [19] because of its low cost, light weight, reliability, compactness and free maintenance as it has no moving parts. It has an adjustable temperature range and cools without using any refrigerant or electricity.

The results presented in this paper show that the COP of the VT can be enhanced by adjusting the cold orifice to tube diameter ratio $\left(d_{c} / D\right)$ and the length to the tube diameter ratio while depending on the adjusted cold mass fraction. This opens a new door to research on enhancing the performance of the VT based on the requirements of the application.

\section{Energy Separation inside the RHVT}

An energy separation occurs in the vortex tube between the cold and hot streams which causes the temperature changes between the inlet and exit streams. Many researchers suggested various theories to explain the energy separation inside the vortex tube. For example, Ahlborn [20] [21] suggested that the RHVT is a refrigeration device that can be modeled and analyzed as a classic thermodynamic refrigeration cycle with significant temperature splitting, refrigerant and coolant loops, expansion and compression loops and heat exchangers. A secondary circulation is formed in the tube and acts as a refrigerant to transfer the energy from the cold stream to the hot stream. Some researchers [1] [22] [23] [24] reported that the energy separation inside the RHVT is due to work transfer caused by a torque produced by viscous shear between inner and outer stream. Kurosaka [25] attempted to explain the energy separation inside the VT by acoustic streaming. He 
proposed that the energy separation is due to damping of acoustic streaming.

The effect of friction and turbulence in the VT has always been a major concern of many researchers and was considered by some researchers as the reason for energy separation. For example, using a simple vortex tube model with CFX software and $\kappa$ - $\varepsilon$ turbulence model, Kazantseva et al. [26] attributed the energy separation inside the VT to the energy and gas dynamic interaction of vortices inside the VT. Behara et al. [27] modeled the RHVT using STAR-CD software and concluded that the energy separation inside the VT exists due to the shear work and heat transfer between the hot and cold streams. Bovand et al. [28] studied a $3 \mathrm{D}$ model of the VT and concluded that a large portion of the energy transfer inside the RHVT is due to the tangential viscous shear. Aljuwayehl et al. [1] explained the operation inside the VT by the existence of viscous shear acting on a control rotating surface separating the cold and hot flow regions. A torque is produced which causes work transfer between the cold and hot flows. El May et al. [29] reported the formation of a great amount of tangential shear stress of the flow near the wall of the tube, and proposed that the tangential shear work can be considered the most important mechanism of energy separation in the tube. Abdelghany and Kandil [30] presented an operational theory for the vortex tube such the mechanism inside the tube is in analogy to the gas refrigeration cycle (reversed Brayton cycle) where the inner vortex acts as a turbine and that outer vortex acts as a compressor. They [30] concluded that a power transfer exist between bother vortices in which the inner vortex loses energy and the outer vortex gains energy based on the transfer of angular momentum between both vortices.

Some researchers noted the existence of secondary circulations in the vortex tube. They attributed the energy separation to the secondary circulations. For example, Behara et al. [31] confirmed the existence of secondary circulations inside the RHVT at small cold orifice to tube diameter ratio $\left(d_{c} / D\right)$ and that such circulations become weak as the $d_{c} / D$ ratio increases and they disappear at $d_{c} / D$ ratios higher than 0.583 . They used a CFD model of the RHVT and showed that the total energy transfer was reduced by $21 \%$ due to the existence of secondary circulation. Therefore, they concluded that it can be a performance degrading mechanism. Such conclusion was confirmed by Farouk [32] [33] using a large eddy simulation (LES) technique on a CFD model of the VT which showed that the secondary circulation resulted in enhancing the mixing between cold and hot flow which increased the temperature of air exiting at cold outlet. Also, Bovand et al. [28] confirmed that the secondary circulations are performance degrading mechanism. Recently, Kandil and Abdelghany [34] investigated the existence of secondary circulations in the vortex tube at different cold orifice to tube diameter ratio $\left(d_{c} / D\right)$ cases. It was confirmed [34] that operating at high cold mass fraction doesn't have any effect on the formation of secondary circulations. Nevertheless, when operating at low $d_{c} / D$ ratio secondary circulations are formed near the cold outlet but only at low cold mass fraction. They concluded that the secondary circulations have almost no effect in degrading the 
performance of the vortex tube.

\section{Performance Optimization of the RHVT}

The performance of the RHVT is affected by geometrical properties such as the length to tube diameter ratio $(L / D)$ and cold orifice to tube diameter ratio $\left(d_{c} / D\right)$. The length to tube diameter ratio $L / D$ is a very important parameter that attracted the interest of many researches s such as [1] [2] [35] [36] [37] [38] [39]. For example, Bramo and Pourmahmoud [2] [35] [37] conducted a study on the $L / D$ ratio effect on the performance of the VT at cold mass fraction of 0.3 (at the maximum cooling effect) and concluded that at $L / D$ ratio of 9.3 the VT has the highest total temperature change. Almost all the other $L / D$ ratios have the same performance and that the high performance at $L / D$ ratio of 9.3 is due to the stagnation point along the centerline of the tube. Patel and Bartaria [38] showed that as $L / D$ increases $\Delta T_{\text {total }}$ increases to reach its maximum value at $L / D$ ratio of 30 after which the performance of the VT decreases. They reported that the performance of the tube in terms of maximum temperature difference between the hot and cold outlets, $\Delta T=T_{h}-T_{c}$, increases with increasing $L / D$ ratio up to a critical value after which the performance degrades. Aydin and Baki [40] confirmed that there is an optimum value for the $L / D$ ratio for the vortex tube. Maurya and Bhavsar [36] concluded that as the $L / D$ ratio increases $\Delta T_{\text {total }}$ increases to reach an asymptotic state, and to obtain the maximum energy separation effect the $L / D$ ratio should be greater than 10. Aljuwayhel et al. [1] studied the $L / D$ ratio effect on the performance at cold mass fraction of 0.3 , near the maximum refrigeration point, and reported that as the length increases the performance of the tube increases up to a certain length of tube after which the effect of the $L / D$ ratio on the performance becomes negligible. Their results showed that there is a critical length of the VT over which the majority of energy transfer takes place and exceeding this length doesn't affect the energy separation.

Kandil and Abdelghany [34] studied the effect of $(L / D)$ ratio on the performance of the vortex tube at different cold mass fractions of $0.34,0.4,0.428,0.5$ and 0.72 .

The effects of varying $d_{c} / D$ on the performance of the VT was investigated by Maurya and Bhavsar [36] by fixing the length and diameter of the tube at 120 $\mathrm{mm}$ and $10 \mathrm{~mm}$, respectively, and changing the diameter of the cold orifice. The best performance was achieved at the lowest cold temperature $\left(T_{c}\right)$, which is the temperature of air exiting at the cold outlet The cold temperature, $T_{c}$, decreased with increasing $d_{c}$ till a critical diameter where the $d_{c} / D=0.583$ then $T_{c}$ increased significantly. They suggested that the reduction of pressure gradient due to increasing the cold orifice diameter $\left(d_{c}\right)$ is the reason behind the rise of the cold exit temperature after reaching the critical $d_{c}$. Andalibi et al. [41] showed that maximum temperature separation occurs at $d_{c} / D$ ratio of 0.45 and that operating at higher ratios will cause backflow at the cold outlet which will degrade the tube's performance. Nimbalkar and Muller [3] studied the effect 
of the $d_{c} / D$ ratio on the energy separation inside the tube and showed that there is an optimum cold orifice diameter and operating at a lower diameter will result in mixing the cold stream with the hot one and operating at a higher diameter will result in mixing the hot stream with the cold one.

Recently, Kandil and Abdelghany [34] studied the effect of the $d_{c} / D$ ratio on the performance of vortex tube in terms of the cold temperature drop and the hot temperature rise. Their results [34] showed that all the $d_{c} / D$ ratio cases exhibit similar behavior where the cold temperature drop increases when decreasing the cold mass fraction until a certain value of the cold mass fraction after which the cold temperature drop decreases significantly. They explained the reason behind the decrease of the cold temperature drop after certain cold mass fraction by the occurrence of back flow at the cold outlet

The results presented in this paper support and build on the research of Kandil and Abdelghany [34] where the changes in the geometrical parameters of the VT can be adjusted to enhance one parameter which is the COP.

\section{Numerical Model}

An Axisymmetric model of the RHVT was designed and simulated using ANSYS Fluent ${ }^{\circledR}$ software. The model was validated using the experimental measurements of Skye et al. [42]. ANSYS Fluent software solves the following compressible turbulent flow conservation of mass, momentum and energy and state equation [43] (ANSYS Fluent Theory Guide):

Continuity equation in tensor notation:

$$
\frac{\partial \bar{\rho}}{\partial t}+\frac{\partial}{\partial x_{j}}\left(\bar{\rho} \bar{u}_{j}+\overline{\rho^{\prime} u_{j}^{\prime}}\right)=0, \quad j=1,2,3
$$

Momentum equations in tensor notations (all three components):

$$
\begin{aligned}
& \frac{\partial}{\partial t}\left(\bar{\rho} \bar{u}_{i}+\overline{\rho^{\prime} u_{i}^{\prime}}\right)+\frac{\partial}{\partial x_{j}}\left(\bar{\rho} \bar{u}_{i} \bar{u}_{j}+\bar{u}_{i} \overline{\rho^{\prime} u_{j}^{\prime}}\right) \\
& =-\frac{\partial \bar{p}}{\partial x_{i}}+\frac{\partial}{\partial x_{j}}\left(\bar{\tau}_{i j}-\bar{u}_{j} \overline{\rho^{\prime} u_{i}^{\prime}}-\bar{\rho} \overline{u_{i}^{\prime} u_{j}^{\prime}}-\overline{\rho^{\prime} u_{i}^{\prime} u_{j}^{\prime}}\right)
\end{aligned}
$$

Where

$$
\bar{\tau}_{i j}=\mu\left[\left(\frac{\partial \bar{u}_{i}}{\partial x_{j}}+\frac{\partial \bar{u}_{j}}{\partial x_{i}}\right)-\frac{2}{3} \delta_{i j} \frac{\partial \bar{u}_{k}}{\partial x_{k}}\right]
$$

Energy Equation:

$$
\begin{aligned}
& \frac{\partial}{\partial t}\left(\bar{\rho} \bar{H}+\overline{\rho^{\prime} H^{\prime}}\right)+\frac{\partial}{\partial x_{j}}\left(\bar{\rho} \bar{u}_{j} \bar{H}+\bar{\rho} \overline{u_{j}^{\prime}} \overline{H^{\prime}}+\overline{\rho^{\prime} u_{j}^{\prime}} \bar{H}+\overline{\rho^{\prime} u_{j}^{\prime} H^{\prime}}+\bar{u}_{j} \overline{\rho^{\prime} H^{\prime}}-k \frac{\partial \bar{T}_{i}}{\partial x_{j}}\right) \\
& =\frac{\partial \bar{\rho}}{\partial t}+\frac{\partial}{\partial x_{j}}\left[\bar{u}_{i}\left(-\frac{2}{3} \mu \delta_{i j} \frac{\partial \bar{u}_{k}}{\partial x_{k}}\right)+\mu \bar{u}_{i}\left(\frac{\partial \bar{u}_{j}}{\partial x_{i}}+\frac{\partial \bar{u}_{i}}{\partial x_{j}}\right)\right. \\
& \left.-\frac{2}{3} \mu \delta_{i j} \overline{u_{i}^{\prime} \frac{\partial u_{k}^{\prime}}{\partial x_{k}}}+\mu\left(\overline{u_{i}^{\prime} \frac{\partial u_{j}^{\prime}}{\partial x_{i}}}+\overline{u_{i}^{\prime} \frac{\partial u_{i}^{\prime}}{\partial x_{j}}}\right)\right], \quad i, j, k=1,2,3
\end{aligned}
$$


Equation of State (ideal gas law)

$$
p=\rho R T
$$

where $\delta_{i j}$ is the Kronecker delta function $\left(\delta_{i j}=1\right.$ if $i=j$ and $\delta_{i j}=0$ if $i \neq j) ; \tau_{i j}$ denotes viscous stress tensor; $H$ represents the total enthalpy; $T$ is the static temperature, $p$ is the pressure, $\rho$ is the density and $R$ is the universal gas constant at standard conditions.

\subsection{Turbulence Model}

The results of the CFD model of the RHVT using the $\kappa-\varepsilon$ Turbulence model showed the best agreement with the experimental results of Skye et al. [42]. Therefore, the $\kappa-\varepsilon$ Turbulence model was selected to simulate the turbulence inside the VT in this study.

The geometry used in the current CFD model is based on the Exair ${ }^{\mathrm{TM}} 708$ slpm vortex tube used by Skye et al. [42] as shown in Figure 1. The current model shown in Figure 2 is an axisymmetric model of the tube with matching geometrical properties to the VT used by Skye et al. [42], where the working tube length is $106 \mathrm{~mm}$, tube diameter is $11.4 \mathrm{~mm}$ and cold exit diameter is $6.2 \mathrm{~mm}$.

The results of the CFD model of the VT became mesh independent when the number of elements reached 17,000 elements. Due to the complexity and sensitivity of the flow inside the VT, the time step of the solution had to be very small

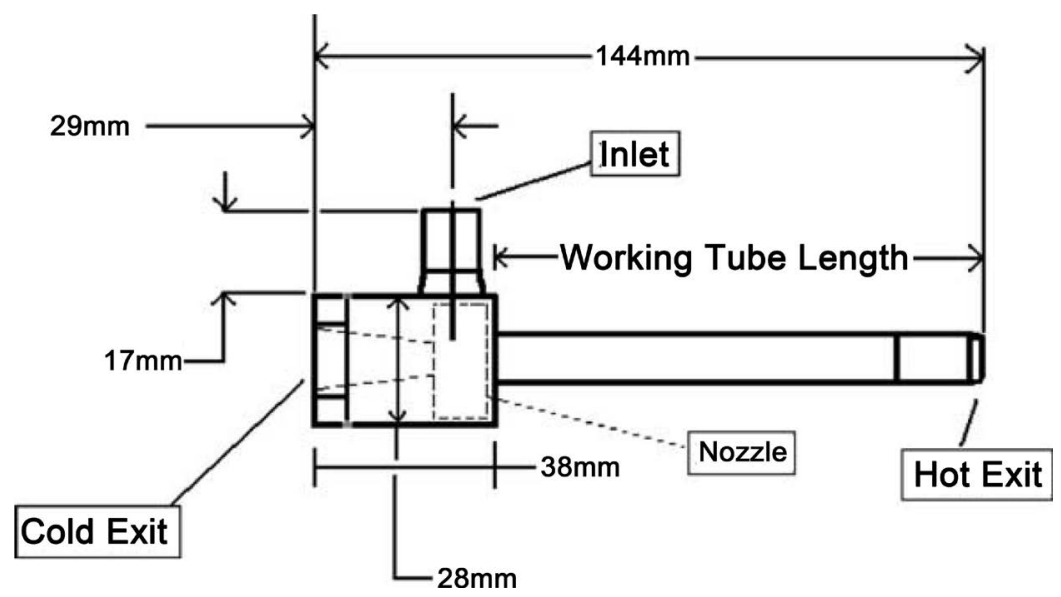

Figure 1. Schematic of vortex tube used in the experiment [42].

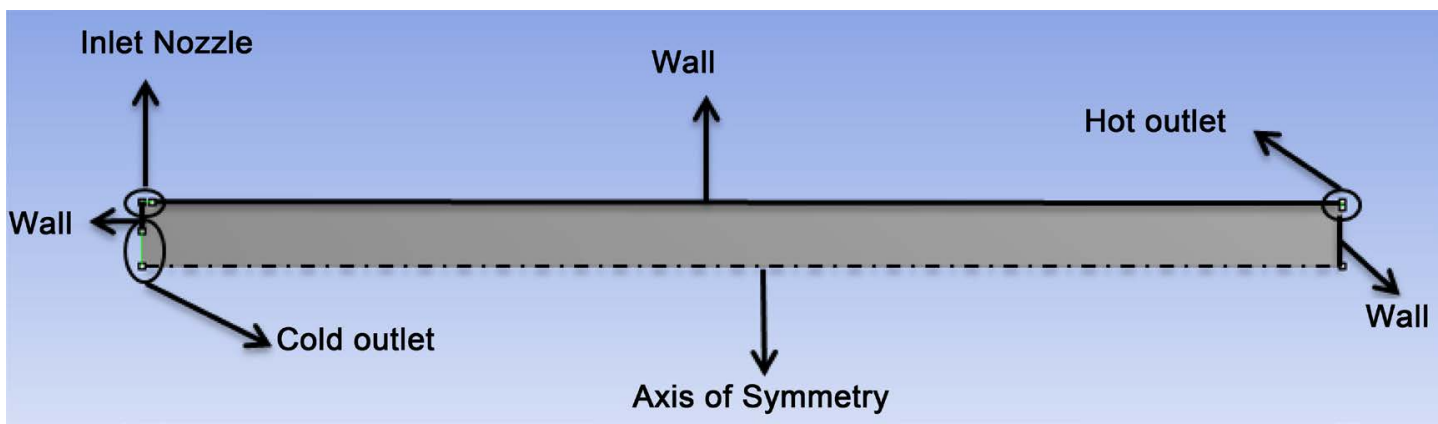

Figure 2. Current CFD Model of the RHVT. 
to allow converge such that the computation time of one simulation ranged from 12 to 48 hours using 8 processors on a $3.64 \mathrm{GHz} \mathrm{HP}$ workstation Z800 with 16 GB Ram.

\subsection{Boundary Conditions}

The experimental data from Skye et al. [42] provided some of the boundary conditions for the inlet nozzles and both outlets while the rest of the data were acquired from different previous CFD models [2] [35] which were implemented based on the current configuration. The boundary conditions are summarized in Table 1.

\subsection{Numerical Model Validation}

The current CFD model was validated by comparing its results with the experimental measurements of Skye et al. [42] using the cold temperature drop $\left(\Delta T_{c}\right)$, and the hot temperature rise $\left(\Delta T_{h}\right)$ defined as the difference in temperatures between the outlet hot air and the inlet air.

Figure 3 shows the comparison of the cold temperature drop of the current model with the experimental measurements and the computational results of Skye et al. [42].

The results in Figure 3 show that the cold temperature drop increases as the cold mass fraction $\left(\mu_{c}\right)$, which is the ratio between the cold air outlet mass flow rate divided by the inlet mass flow rate, decreases up to a maximum $\Delta T_{c}$ of $40.4 \mathrm{~K}$ at a cold mass fraction of 0.34 after which $\Delta T_{c}$ decreases to reach a temperature of $31.7 \mathrm{~K}$ at $\mu_{c}$ of 0.2099 . The $\Delta T_{c}$ reaches a minimum value of $20 \mathrm{~K}$ at $\mu_{c}$ of 0.87 which shows that as the cold mass fraction increases to a maximum value the cold temperature drop decreases to its minimum value. It is noted that the current model has better agreement with the experimental measurements than that of Skye et al. [42] model.

Figure 4 shows the comparison between the hot temperature rise results of the current study with the experimental measurements and the computational results of Skye et al. [42].

The results show that the hot temperature rise increases as the cold mass fraction increases to reach a maximum value of $86.7 \mathrm{~K}$ at cold mass fraction of 0.87 . Increasing the cold mass fraction further will be impractical due to the very low

Table 1. Boundary conditions used in the current study.

\begin{tabular}{cl}
\hline Boundary Condition & $\begin{array}{l}\text { Type and Parameter of boundary condition } \\
\text { Inlet nozzles }\end{array}$ \\
Cold outlet & $\begin{array}{l}\text { Mass flow inlet boundary condition with mass flow rate of } 8.35 \mathrm{~g} / \mathrm{s}, \\
\text { total temperature of } 294.2 \mathrm{~K}\end{array}$ \\
Hot outlet & Pressure outlet \\
Tube wall & No slip boundary conditions with adiabatic wall \\
Tube axis & Axisymmetric swirl conditions \\
\hline
\end{tabular}




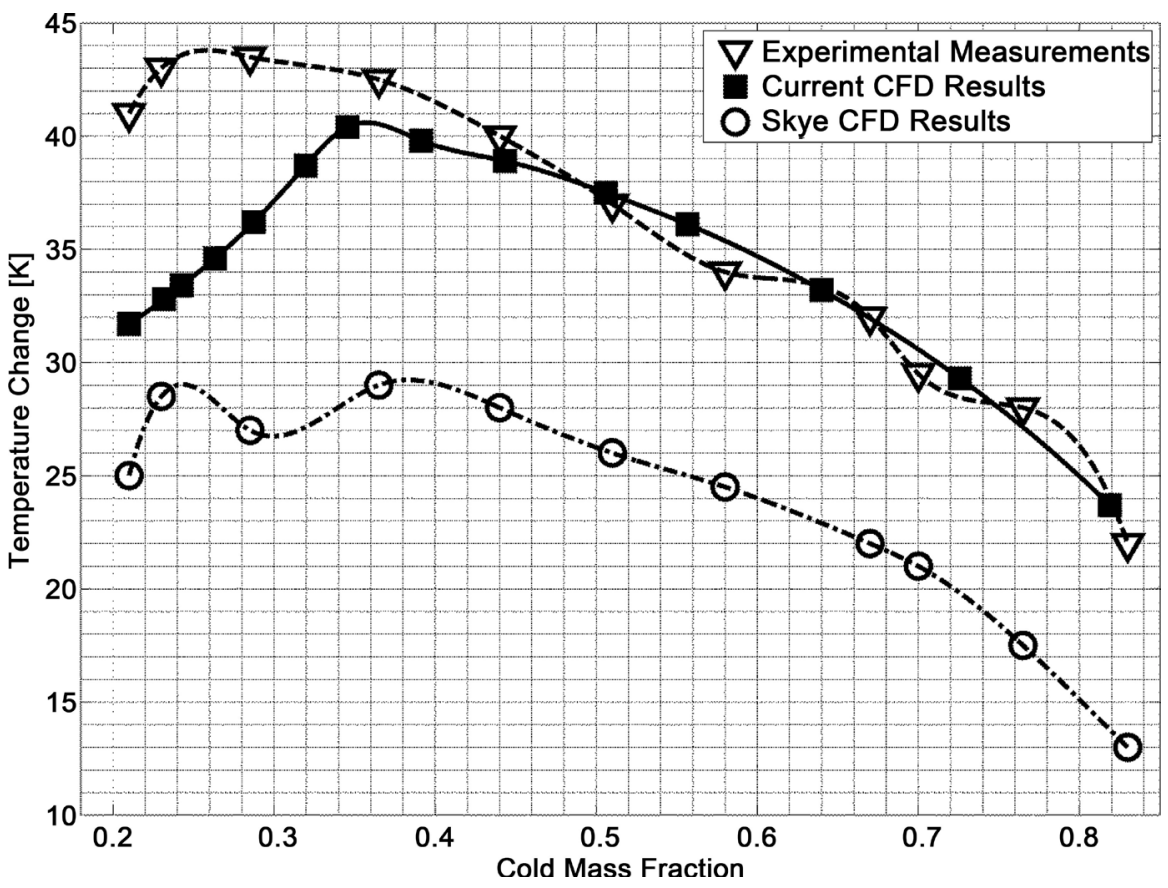

Figure 3. Comparison of the cold temperature drop results with the experimental measurements and computational results of Skye et al. [42].

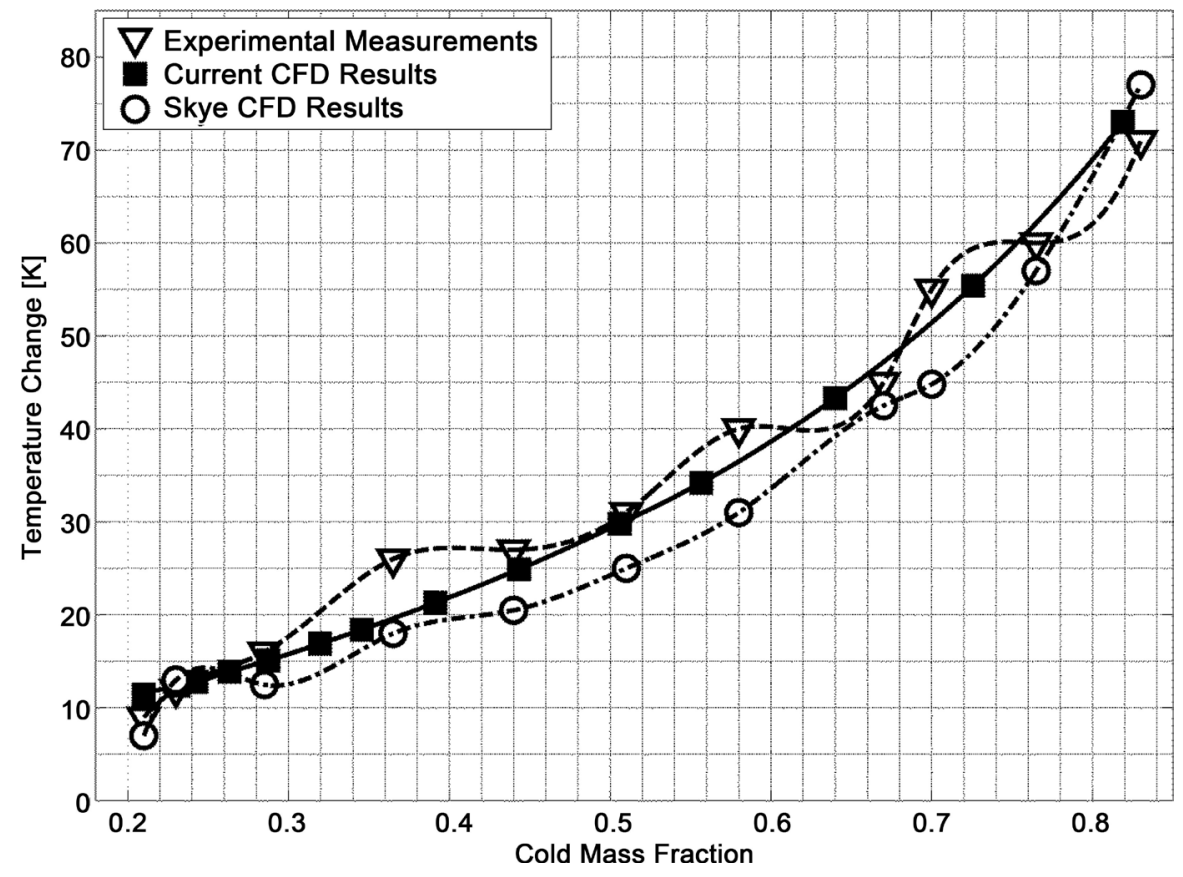

Figure 4. Comparison of the hot temperature rise results with the experimental measurements and computational results of Skye et al. [42].

flow rate of air from the hot outlet. The results show also that at very low cold mass fraction, the hot temperature rise decreases till it reaches a minimum value of $11.4 \mathrm{~K}$ at cold mass fraction of 0.2099 . The results show also that when operating at cold mass fractions from 0.2 to 0.45 the increase in temperature rise is slow while as the cold mass fraction increases, the increase in temperature rise 
becomes rapid especially at very high cold mass fractions. The comparison shows that the current model has better agreement with the experimental measurements than that of Skye et al. [42] model.

\section{Performance Optimization of the RHVT}

\subsection{Effects of the Length to Tube Diameter Ratio on the Total Coefficient of the Vortex Tube ( $\left.C O P_{\text {total }}\right)$}

The performance of the VT was determined by Kandil and Abdelghany [34] in terms of total temperature change. When studying the performance of the RHVT, not only the hot temperature rise or the cold temperature drop should considered but also the cold mass fraction, the pressure at the inlet and the pressure at the cold outlet. The VT can be used for cooling as it may be used for heating therefore a coefficient of performance (COP) for the two operations are defined.

The coefficient of performance for the RHVT when it is used as a refrigerator is the cooling power $\dot{Q}_{c}$ divided by the input power $\boldsymbol{P}$. The input power for any refrigeration system is the input to the compressor. But for a RHVT system a compressed air source is used which makes it difficult to define the input power. Fulton [44] proposed that the work used to compress the air through a reversible isothermal compression process from the exhaust pressure up to the input pressure the input work is expressed as follows:

$$
\boldsymbol{P}=\dot{m}_{\text {in }} R_{m} T_{i n} \ln \left(\frac{p_{\text {in }}}{p_{c}}\right)
$$

where

$$
\dot{Q}_{c}=\dot{m}_{c} c_{p}\left(T_{i n}-T_{c}\right)
$$

where $R_{m}$ is the specific gas constant, $p_{i n}$ is the input pressure and $p_{c}$ is the cold exit pressure

Therefore the COP of the RHVT as a cooler is expressed as

$$
\mathrm{COP}_{c}=\frac{\gamma}{\gamma-1} \frac{\mu_{c}\left(T_{i n}-T_{c}\right)}{T_{\text {in }} \ln \left(\frac{p_{\text {in }}}{p_{c}}\right)}
$$

The COP for the RHVT when it is used as a heat pump is defined as the heating power $\dot{Q}_{h}$ divided by the input power $\boldsymbol{P}$. The input power used by the system takes the same from as the one used for the cooling RHVT

Therefore, the COP of the RHVT as a heat pump is expressed as

$$
C O P_{h}=\frac{\gamma}{\gamma-1} \frac{\left(1-\mu_{c}\right)\left(T_{h}-T_{\text {in }}\right)}{T_{\text {in }} \ln \left(\frac{p_{\text {in }}}{p_{c}}\right)}
$$

The total performance of the RHVT can be determined using the summation of the COP as a cooler and as a heat pump which is expressed as: 


$$
C O P_{\text {total }}=C O P_{c}+C O P_{h}
$$

Figure 5 shows the relationship between the $C O P_{\text {total }}$ and different $L / D$ ratios at cold mass fractions of $0.34,0.4$ and 0.43 . The results in Figure 5 at cold mass fraction of 0.34 show that at $L / D$ ratio of 2.8 the $C O P_{\text {total }}$ is 0.3309 and as the $L / D$ increases the $C O P_{\text {total }}$ increases to reach a maximum value of 0.3746 at $L / D$ of 7.02 with a difference of 0.0437 from the $C O P_{\text {total }}$ at the lowest $L / D$ ratio of 2.8. After which any further increase in the $L / D$ ratio will result in a decrease in the $C O P_{\text {total }}$ and the performance of the VT to reach a value of 0.3601 at $L / D$ ratio of 20.2.

The performance of the VT in terms of $C O P_{\text {total }}$ at different $L / D$ ratios was studied at different values of cold mass fraction. The results in Figure 5 and Figure 6 at cold mass fraction of 0.4 show that the $C O P_{\text {total }}$ at $L / D$ ratios above 3.5 decreased significantly changing the trend of the curve. Increasing $\mu$ to 0.439 decreased the $C O P_{\text {total }}$ even more such that the relation between the $C O P_{\text {total }}$ and the $L / D$ ratio at $\mu=0.72$ in Figure 6 shows a completely different pattern than that at $\mu=0.34$ shown in Figure 5 where the lowest $L / D$ ratio of 2.8 has the highest $C O P_{\text {total }}$ of 0.4936 . As the $L / D$ ratio increases the $C O P_{\text {total }}$ decreases to reach an asymptotic value of 0.476 at $L / D$ ratio of 20.2.

These results show that the $C O P_{\text {total }}$ at different $L / D$ ratios is dependent upon the cold mass fraction, where at low cold mass fraction, as the $L / D$ increases the $C O P_{\text {total }}$ increases to reach a maximum value at a critical $L / D$ ratio. Any further increase in the $L / D$ ratio will result in decreasing the $C O P_{\text {total }}$. While as the cold mass fraction increases the difference between the maximum and minimum $C O P_{\text {total }}$ is reduced from 0.04 at $\mu=0.34$ to 0.0086 at $\mu=0.5$. Any further increase in the cold mass fraction will change the trend of the curve

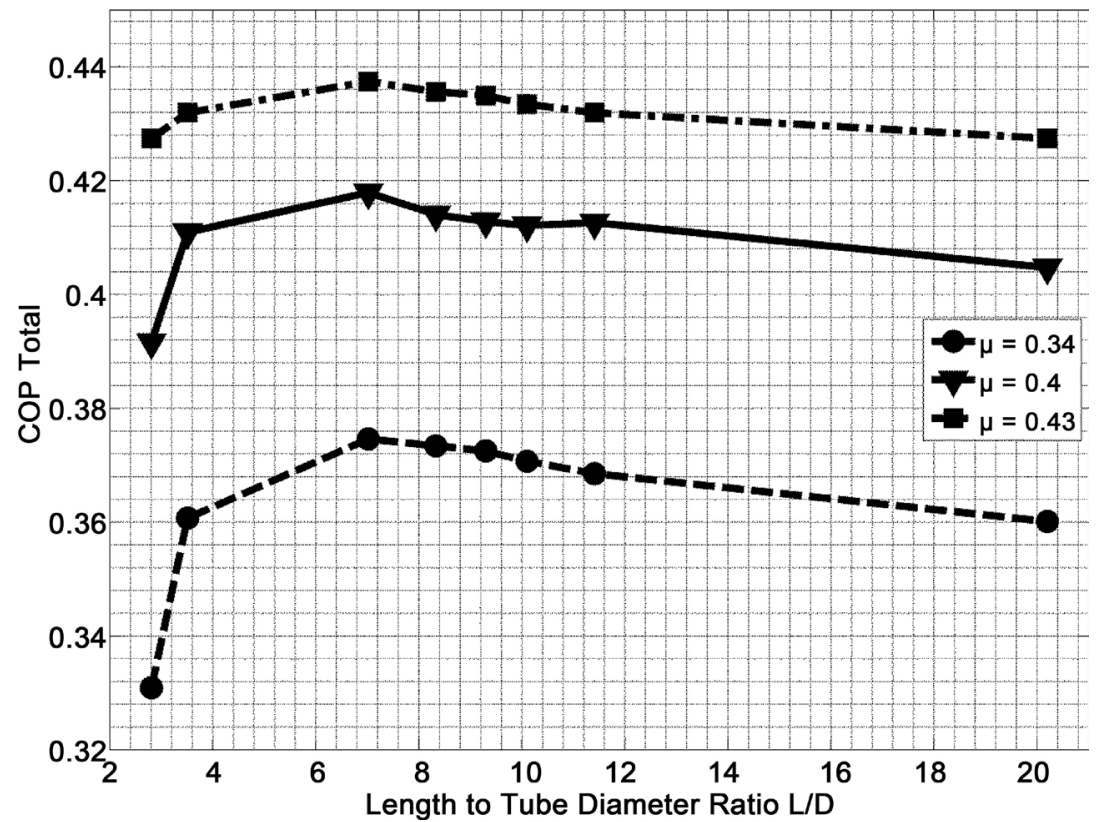

Figure 5. Total COP of the VT at different $L / D$ ratios at cold mass fractions of $0.34,0.4$ and 0.43 . 


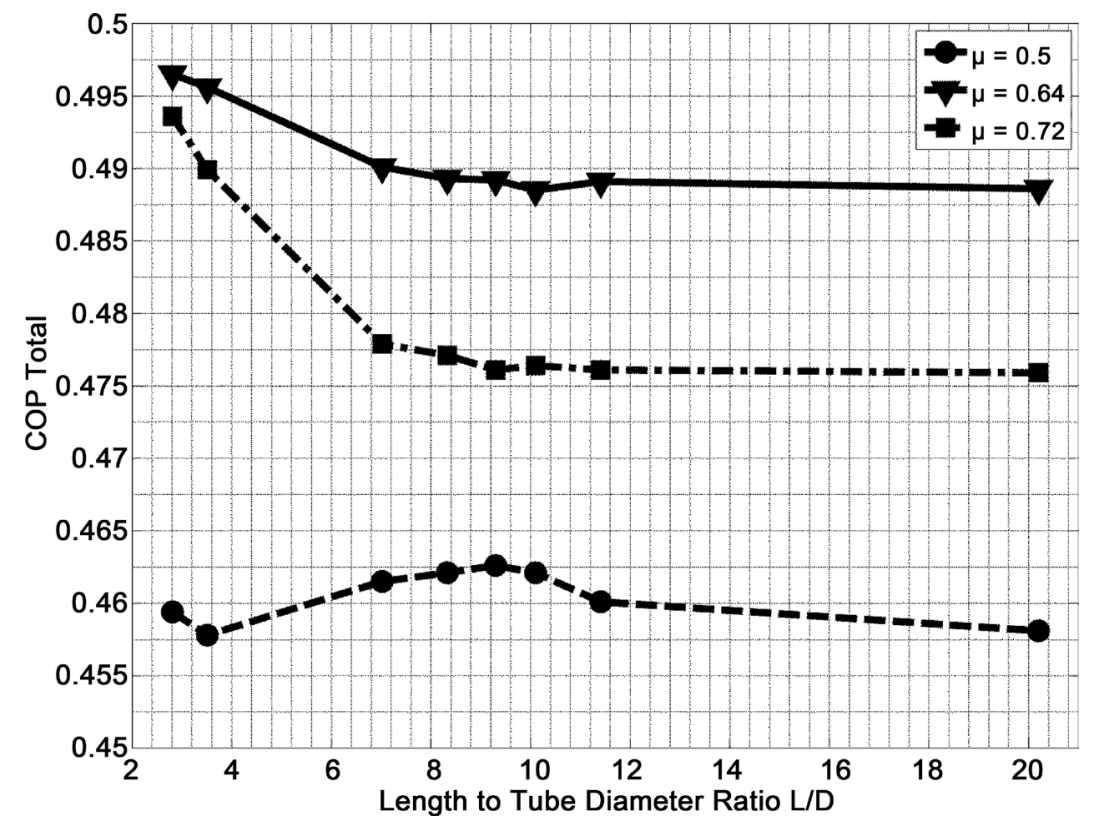

Figure 6. Total COP of the VT at different $L / D$ ratios at cold mass fractions of $0.5,0.64$ and 0.72 .

between the $C O P_{\text {total }}$ and different $L / D$ ratios such that the lowest $L / D$ ratio has the highest $C O P_{\text {total }}$ and as the $L / D$ ratio increases the $C O P_{\text {total }}$ decreases to reach asymptotic value at critical $L / D$ ratio.

In Figure 6, it is shown that the $\operatorname{COP}_{\text {total }}$ at a cold mass fraction of 0.64 is higher than that at any other cold mass fraction. Such results show that the best $\mathrm{COP}_{\text {total }}$ value will be achieved when operating the tube at a cold mass fraction of 0.64 at any length to tube diameter ratio.

Such results don't follow the same pattern of the results of total temperature of Kandil and Abdelghany [34] where the best performance of the VT in terms of total temperature is when operating at the maximum possible cold mass fraction. This can be interpreted that the $C O P_{\text {total }}$ depend not only on the cold and hot temperature changes as the total temperature change but also on the cold mass fraction and the pressure at the inlet and cold outlet.

\subsection{Effects of the Cold Orifice to Tube Diameter Ratio on the Performance of the Vortex Tube in Terms of COP}

The cold orifice diameter is an important parameter that affects the performance of the VT. Therefore, several trials were done to optimize the performance of the tube of a diameter of $11.4 \mathrm{~mm}$ by varying the cold orifice diameter to pipe diameter ratio, $d_{c} / D$.

\subsubsection{Highest COP Cold $\left(C_{C P}\right)$}

When studying the performance of the RHVT taking into consideration not just the highest temperature drop but also the cold mass fraction, the pressure at the inlet and the pressure at the cold outlet, a new dimensionless parameter had to be defined to combine the effect of all the previously mentioned parameters on 
the performance of the vortex tube. This dimensionless parameter is the $C O P_{c}$ which was defined by Equation (8). Figure 7 shows the relationship between the $\mathrm{COP}_{c}$ and the cold mass fraction.

It is shown in Figure 7 that all $d_{c} / D$ ratio cases follow a similar pattern whereas the cold mass fraction increases the $\mathrm{COP}_{c}$ increases till a critical cold mass fraction which is almost the same in all cases of value of 0.64 after which the $C_{c}$ decreases with any further increase in cold mass fraction. The results show that the $d_{c} / D$ ratio of 0.6316 has the highest $C O P_{c}$ of 0.319 at a cold mass fraction of 0.64 .

It is shown in Figure 7 that at cold mass fraction of 0.3 the $C O P_{c}$ of the $d_{c} / D$ ratios above 0.5 drops to be lower than the $C O P_{c}$ of the $d_{c} / D$ ratios below 0.5 but the pattern starts when the highest $d_{c} / D$ ratio of 0.6316 drops at cold mass fraction of 0.4. These results show that decreasing the cold mass fraction beyond a threshold, especially for high $d_{c} / D$ ratios, causes a drop in $\mathrm{COP}_{c}$, resulting in an inversely proportional relationship beyond this threshold.

\subsubsection{Highest COP Hot $\left(\mathrm{COP}_{h}\right)$}

When studying the performance of the RHVT taking into consideration not just the highest temperature rise but also the hot mass fraction, the pressure at the inlet and the pressure at the cold outlet, a new dimensionless parameter had to be defined to combine the effect of all the previously mentioned parameters on the performance of the vortex tube. This dimensionless parameter is the $C_{C O P}$ which was defined by Equation (9). Figure 8 shows the relationship between the $\mathrm{COP}_{h}$ and the cold mass fraction.

It is shown in Figure 8 that all $d_{c} / D$ ratio cases follow a similar pattern whereas cold mass fraction increases the $C O P_{h}$ increases up to a critical cold

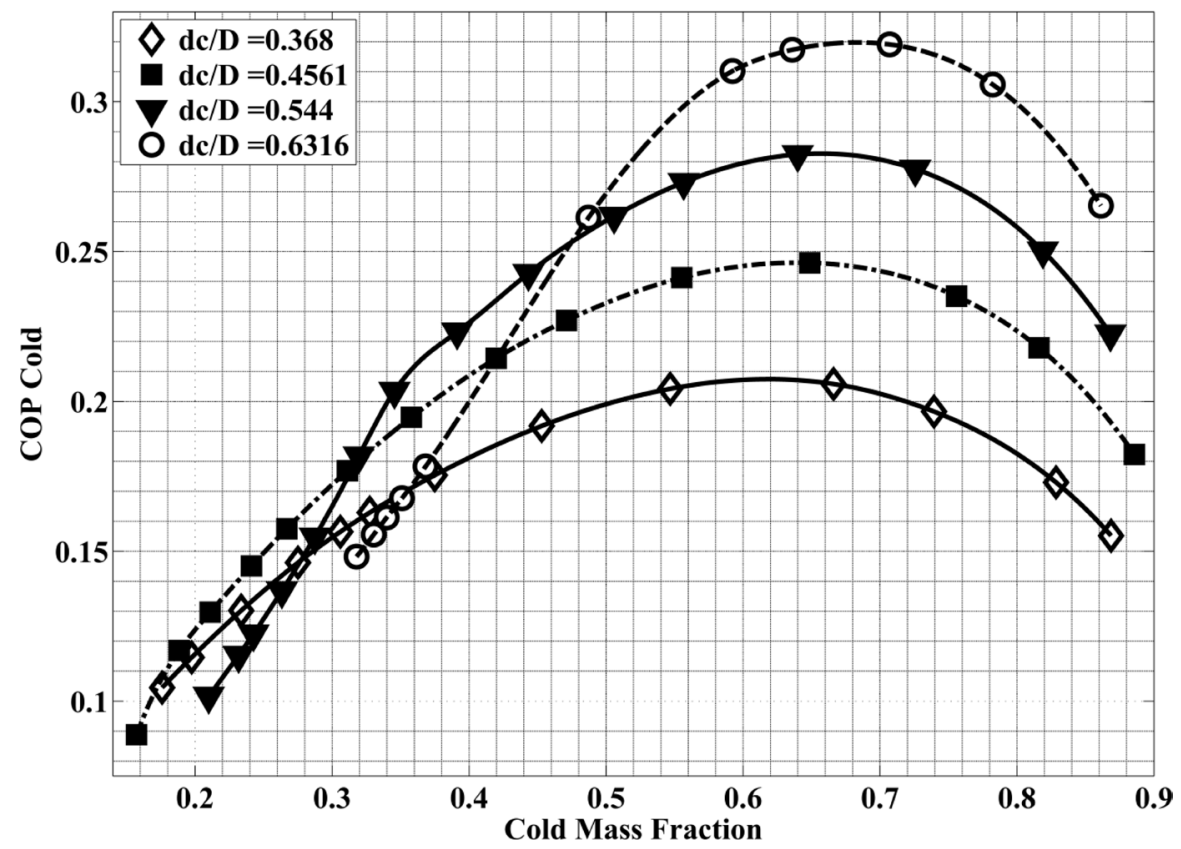

Figure 7. Cold COP of the RHVT at different $d_{d} D$ ratio. 


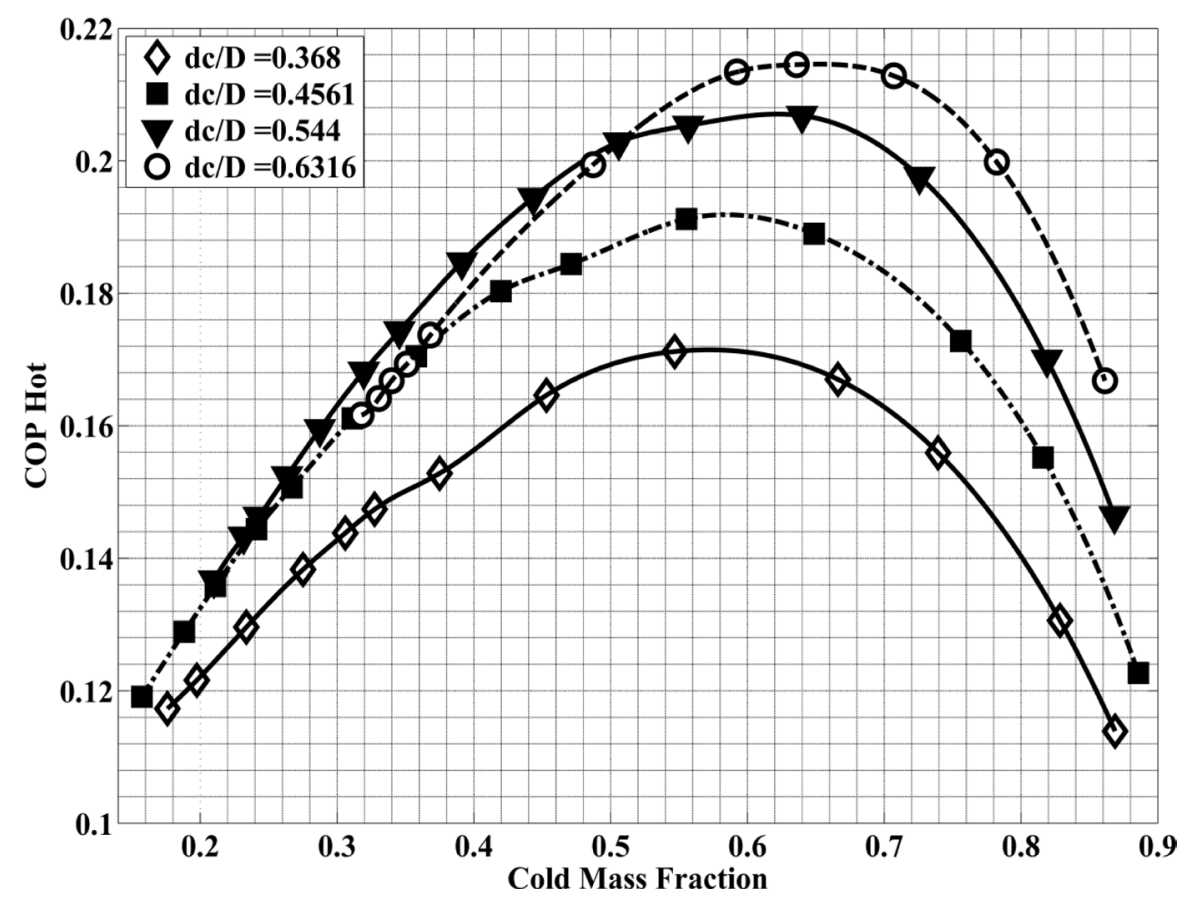

Figure 8. Hot COP of the RHVT at different $d_{d} D$ ratio.

mass fraction which is almost the same value of 0.64 in all cases after which any further increase in the cold mass fraction will result in decreasing the $\mathrm{COP}_{h}$. The highest $C O P_{c}$ of different $d_{c} / D$ ratio cases existed at this exact cold mass fraction as stated in the previous Section 5.2.1. The $d_{c} / D$ ratio of 0.6316 has the highest $\mathrm{COP}_{h}$ of 0.2145 at cold mass fraction of 0.64 .

\subsubsection{Highest COP Total ( $\left.C O P_{\text {total }}\right)$}

From the previous sections, it was noted that the highest $C O P_{c}$ and $C O P_{h}$ were at a cold mass fraction of 0.64 for all $d_{c} / D$ ratio cases The $C O P_{\text {total }}$ was defined in Equation (10) as the summation of the $\mathrm{COP}_{c}$ and $\mathrm{COP}_{h}$, therefore when studying the performance of the RHVT in terms of the $C O P_{\text {total }}$, the maximum $C O P_{\text {total }}$ for all the different $d_{c} / D$ ratio cases should exist at cold mass fraction of 0.64 which is confirmed in Figure 9 which shows the relationship between the $C O P_{\text {total }}$ and the cold mass fraction. It is shown in Figure 9 that the $d_{c} / D$ ratio of 0.6361 has the highest $C O P_{\text {total }}$ of 0.534 at cold mass fraction of 0.64 .

It is noted from the results in Section 5.1 and Section 5.2 that the best performance of the vortex tube in terms of $C O P_{\text {total }}$ occurs when operating the vortex tube at a cold mass fraction of 0.64 regardless of the length to tube diameter ratio or the cold orifice to tube diameter ratio.

For Future research, these results can be more investigated in terms of flow analysis using 3D modeling of the RHVT to gain more insights about what actually occurs at the cold mass fraction of 0.64 . Building on these results, the flow visualization at different $d_{c} / D$ ratios at this cold mass fraction will also be very beneficial. 


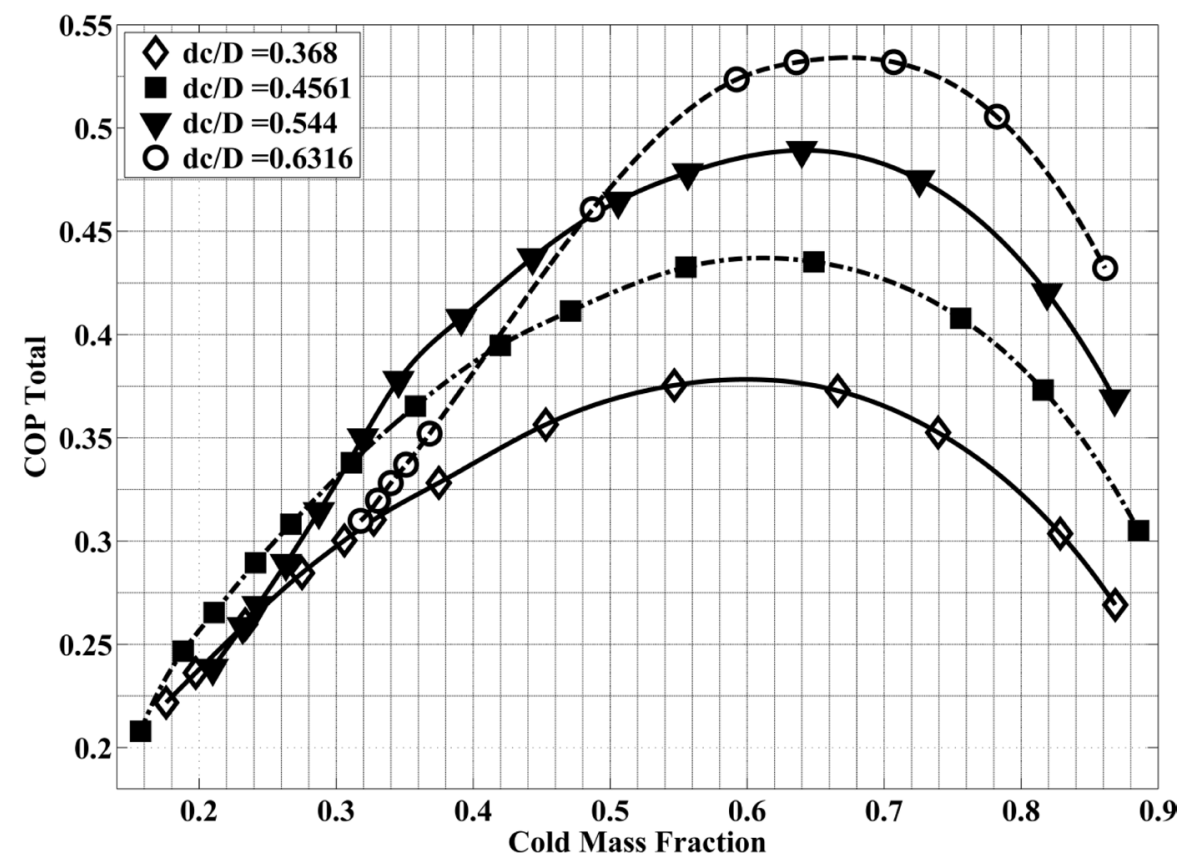

Figure 9. Total COP of the RHVT at different $d_{d} D$ ratio.

\section{Conclusions}

The results of the current model are in good agreement with the available experimental measurements. Many geometrical parameters affect the performance of the tube. In this study, the length to tube diameter ratio effect in terms of $C O P_{\text {total }}$ was investigated and the results showed that its effect on the performance of the tube is different at different cold mass fractions where the maximum $C O P_{\text {total }}$ at any length to tube diameter ratio occurs at cold mass fraction of 0.64 .

Also the effect of the cold orifice to tube diameter ratio on $C O P_{c}, C O P_{h}$ and $C O P_{\text {total }}$ was investigated and the results showed that all the studied VTs at different $d_{c} / D$ ratios have the maximum $C O P_{c}$ and the maximum $C O P_{h}$ at a cold mass fraction of 0.64 . The highest $d_{c} / D$ ratio of 0.6361 has the highest $C O P_{c}$ and $C O P_{h}$.

It can be concluded that the best performance of the studied vortex tube at any $L / D$ or $d_{c} / D$ ratio occurs at a cold mass fraction of 0.64 . Future investigation of the physical properties of the tube at such cold mass fraction and its relation to other operating points of the vortex tube should be considered.

\section{References}

[1] Aljuwayhel, N.F., Nellis, G.F. and Klein, S.A. (2005) Parametric and Internal Study of the Vortex Tube Using a CFD Model. International Journal of Refrigeration, 28, 442-450. https://doi.org/10.1016/j.ijrefrig.2004.04.004

[2] Bramo, A. and Pourmahmoud, N. (2010) A Numerical Study on the Effect of Length to Diameter Ratio and Stagnation Point on the Performance of Counter Flow Ranque-Hilsch Vortex Tubes. Australian Journal of Basic and Applied Sciences, 4, 4943-4957. 
[3] Nimbalkar, S.U. and Muller, M.R. (2009) An Experimental Investigation of the Optimum Geometry for the Cold End Orifice of a Vortex Tube. Applied Thermal Engineering, 29, 509-514. https://doi.org/10.1016/j.applthermaleng.2008.03.032

[4] Rafiee, S.E. and Rahimi, M. (2013) Experimental Study and Three-Dimensional (3D) Computational Fluid Dynamics (CFD) Analysis on the Effect of the Convergence Ratio, Pressure Inlet and Number of Nozzle Intake on Vortex Tube Performance-Validation and CFD Optimization. Energy, 63, 195-204.

https://doi.org/10.1016/j.energy.2013.09.060

[5] Dutta, T., Sinhamahapatra, K.P. and Bandyopdhyay, S.S. (2010) Comparison of Different Turbulence Models in Predicting the Temperature Separation in a Ranque-Hilsch Vortex Tube. International Journal of Refrigeration, 33, 783-792. https://doi.org/10.1016/j.ijrefrig.2009.12.014

[6] Aydin, O., Markal, B. and Avci, M. (2010) A New Vortex Generator Geometry for a Counter-Flow Ranquee-Hilsch Vortex Tube. Applied Thermal Engineering, 30, 2505-2511. https://doi.org/10.1016/j.applthermaleng.2010.06.024

[7] Thakare, H.R. and Parekh, A.D. (2014) CFD Analysis of Energy Separation of Vortex Tube Employing Different Gases, Turbulence Models and Discretisation Schemes. International Journal of Heat and Mass Transfer, 78, 360-370. https://doi.org/10.1016/j.ijheatmasstransfer.2014.06.083

[8] Ranque, G.J. (1933) Methods and Apparatus for Obtaining from a Fluid under Pressure Two Currents of Fluids at Different Temperatures. Patent No. 1,952,281.

[9] Hilsch, R. (1947) The Use of the Expansion of Gases in a Centrifugal Field as Cooling Process. The Review of Scientific Instruments, 18, 108-113. https://doi.org/10.1063/1.1740893

[10] Xue, Y., Arjomandi, M. and Kelso, R. (2014) Energy Analysis within a Vortex Tube. Experimental Thermal and Fluid Science, 52, 139-145. https://doi.org/10.1016/j.expthermflusci.2013.09.004

[11] Xue, Y., Arjomandi, M. and Kelso, R. (2012) Experimental Study of the Flow Structure in a Counter Flow Ranque-Hilsch Vortex Tube. International Journal of Heat and Mass Transfer, 55, 5853-5860.

https://doi.org/10.1016/j.ijheatmasstransfer.2012.05.081

[12] Dincer, K., Baskaya, S., Uysal, B.Z. and Ucgul, I. (2009) Experimental Investigation and Exergy Analysis of the Performance of a Counter Flow Ranque-Hilsch Vortex Tube with Regard to Nozzle Cross-Section Areas. International Journal of Refrigeration, 32, 87-94. https://doi.org/10.1016/j.ijrefrig.2008.06.002

[13] Bovand, M., Valipour, M.S., Dincer, K. and Eiamsa-ard, S. (2014) Application of Response Surface Methodology to Optimization of a Standard Ranquee-Hilsch Vortex Tube Refrigerator. Applied Thermal Engineering, 67, 545-553. https://doi.org/10.1016/j.applthermaleng.2014.03.039

[14] Crocker, A.M., White, S.M. and Bremer, F. (2003) Experimental Results of a Vortex Tube Air Separator for Advanced Space Transportation. In: Proceedings of the 39 th Joint Propulsion Conference and Exhibit, AIAA, Huntsville, 4451. https://doi.org/10.2514/6.2003-4451

[15] Balepin, V. and Rosholt, D. (1999) Progress in Air Seperation with the Vortex Tube. In: Proceedings of the 9 th International Space Planes and Hypersonic Systems and Technologies Conference, Norfolk, Virginia, 4884.

[16] Im, S.Y. and Yu, S.S. (2012) Effects of Geometric Parameters on the Separated Air Flow Temperature of a Vortex Tube for Design Optimization. Energy, 37, 154-160. https://doi.org/10.1016/j.energy.2011.09.008 
[17] Zin, K.K., Hansske, A. and Ziegler, F. (2010) Modeling and Optimization of the Vortex Tube with Computational Fluid Dynamic Analysis. Energy Research Journal, 1, 193-196. https://doi.org/10.3844/erjsp.2010.193.196

[18] Gao, C.M., Bosschaart, K.J., Zeegers, J.C.H. and de Waele, A.T.A.M. (2005) Experimental Study on a Simple Ranque-Hilsch Vortex Tube. Cryogenics, 45, 173-183. https://doi.org/10.1016/j.cryogenics.2004.09.004

[19] Liu, X. and Liu, Z. (2014) Investigation of the Energy Separation Effect and Flow Mechanism inside a Vortex Tube. Applied Thermal Engineering, 67, 494-506. https://doi.org/10.1016/j.applthermaleng.2014.03.071

[20] Ahlborn, B.K. and Gordon, J.M. (2000) The Vortex Tube as a Classic Thermodynamic Refrigeration Cycle. Journal of Applied Physics, 88, 3645-3653.

[21] Ahlborn, B.K., Keller, J.U. and Rebhan, E. (1998) The Heat Pump in a Vortex Tube. Journal of Non Equilibrium Thermodynamics, 23, 159-165. https://doi.org/10.1515/jnet.1998.23.2.159

[22] Gao, C. (2005) Experimental Study on the Ranque-Hilsch Vortex Tube. PhD Thesis, Technische Universiteit Eindhoven, Eindhoven.

[23] Arbuzov, V.A., Dubnishchev, Y.N., Lebedev, A.V., Pravdina, M.K. and Yavorskii, N.I. (1997) Observation of Large-Scale Hydrodynamic Structures in a Vortex Tube and the Ranque Effect. Technical Physics Letters, 23, 938-940. https://doi.org/10.1134/1.1261939

[24] Colgate, S.A. and Buchler, J.R. (2000) Coherent Transport of Angular Momentum-The Ranque-Hilsch Tube a Paradigm. Annuals of the New York Academy of Sciences, 898, 105-112. https://doi.org/10.1111/j.1749-6632.2000.tb06166.x

[25] Kurosaka, M. (1982) Acoustic Streaming in Swirling Flow and the Ranque-Hilsch (Vortex-Tube) Effect. Journal of Fluid Mechanics, 124, 139-172. https://doi.org/10.1017/S0022112082002444

[26] Kazantseva, O.V., Piralishvili, S.A. and Fuzeeva, A.A. (2005) Numerical Simulation of Swirling Flows in Vortex Tubes. High Temperature, 43, 608-613. https://doi.org/10.1007/s10740-005-0102-8

[27] Behera, U., Paul, P.J., Dinesh, K. and Jacob, S. (2008) Numerical Investigations on Flow Behaviour and Energy Separation in Ranque-Hilsch Vortex Tube. International Journal of Heat and Mass Transfer, 51, 6077-6089. https://doi.org/10.1016/j.ijheatmasstransfer.2008.03.029

[28] Bovand, M., Valipour, M.S., Eiamsa-ard, S. and Tamayol, A. (2014) Numerical Analysis for Curved Vortex Tube Optimization. International Communications in Heat and Mass Transfer, 50, 98-107. https://doi.org/10.1016/j.icheatmasstransfer.2013.11.012

[29] El May, O.T., Mokni, I., Mhiri, H. and Bournot, P. (2011) CFD Investigation of a Vortex Tube: Effect of the Cold End Orifice in the Temperature Separation Mechanism. Science Academy Transactions on Renewable Energy Systems Engineering and Technology, 1, 84-89.

[30] Abdelghany, S.T. and Kandil, H.A. (2015) Three-Dimensional Computational Investigation of the Power Separation and Flow Anatomy in the Vortex Tube. International Journal of Refrigeration, 20, 21-31.

[31] Behera, U., et al. (2005) CFD Analysis and Experimental Investigations towards Optimizing the Parameters of Ranque-Hilsch Vortex Tube. International Journal of Heat and Mass Transfer, 48, 1961-1973. https://doi.org/10.1016/j.ijheatmasstransfer.2004.12.046

[32] Farouk, T. and Farouk, B. (2007) Large Eddy Simulations of the Flow Field and 
Temperature Separation in the Ranque-Hilsch Vortex Tube. International Journal of Heat and Mass Transfer, 50, 4724-4735.

https://doi.org/10.1016/j.ijheatmasstransfer.2007.03.048

[33] Farouk, T., Farouk, B. and Gustol, A. (2009) Simulation of Gas Species and Temperature Separation in the Counter-Flow Ranque-Hilsch Vortex Tube Using the Large Eddy Simulation Technique. International Journal of Heat and Mass Transfer, 52, 3320-3333. https://doi.org/10.1016/j.ijheatmasstransfer.2009.01.016

[34] Kandil, H.A. and Abdelghany, S.T. (2015) Computational Investigation of Different Effects on the Performance of the Ranque-Hilsch Vortex Tube. Energy, 84, 207-218. https://doi.org/10.1016/j.energy.2015.02.089

[35] Bramo, A. and Pourmahmoud, N. (2011) Computational Fluid Dynamics Simulation of Length to Diameter Ratio Effect on the Energy Seperation in a Vortex Tube. Thermal Science, 15, 833-848. https://doi.org/10.2298/TSCI101004008B

[36] Maurya, R.S. and Bhavsar, K.Y. (2013) Energy and Flow Separation in the Vortex Tube: A Numerical Investigation. International Journal on Theoretical and Applied Research in Mechanical Engineering, 2, 25-32.

[37] Pourmahmoud, N. and Bramo, A. (2011) The Effect of L/D Ratio on the Temperature Separation in the Counterflow Vortex Tube. International Journal of Research and Reviews in Applied Sciences, 6, 60-68.

[38] Patel, R.B. and Bartaria, V.N. (2013) Experimental Investigation \& Numerical Analysis of Ranque Hilsch. International Journal of Engineering Research \& Technology, 2, 1-6.

[39] Dincer, K., Tasdemir, S., Baskaya, S. and Uysal, B.Z. (2008) Modeling of the Effects of Length to Diameter Ratio and Nozzle Number on the Performance of Counterflow Ranque-Hilsch Vortex Tubes Using Artificial Neural Networks. Applied Thermal Engineering, 28, 2380-2390. https://doi.org/10.1016/j.applthermaleng.2008.01.016

[40] Aydin, O. and Baki, M. (2006) An Experimental Study on the Design Parameters of a Counterflow Vortex Tube. Energy, 31, 2763-2772. https://doi.org/10.1016/j.energy.2005.11.017

[41] Andalibi, M.R., Azizi, S.H., Khameneh, P.M. and Janmohammadi, M. (2012) Effect of Diameter and Diameter of Orifice on the Performance of Vortex Tube. International Journal of Science and Engineering Investigations, 1, 89-93.

[42] Skye, H.M., Nellis, G.F. and Klein, S.A. (2006) Comparison of CFD Analysis to Empirical Data in a Commercial Vortex Tube. International Journal of Refrigeration, 29, 71-80. https://doi.org/10.1016/j.ijrefrig.2005.05.004

[43] ANSYS-Fluent. https://www.ansys.com/Products/Fluids/ANSYS-Fluent

[44] Fulton, C.D. (1950) Ranque's Tube. Journal of the American Society of Refrigerating Engineers, 58, 473-479. 